\title{
Ulysses Pernambucano e a questão da "Higiene mental"
}

\author{
Mário Eduardo Costa Pereira
}

Aquele que viria a ser conhecido como o criador da Escola de Psiquiatria Social do Recife, e como um dos expoentes maiores da chamada "Higiene Mental" no contexto brasileiro era, antes de tudo, um homem da ação. Mais do que um psicopatólogo, no sentido estrito da palavra, Ulysses Pernambucano era um psiquiatra que transformava em obras institucionais concretas uma certa concepção de psicopatologia e de terapêutica psiquiátricas baseada na idéia de que as condições socioeconômico-culturais específicas, nas quais estava inscrita uma determinada população, eram determinantes no aparecimento dos transtornos mentais próprios àquele grupo humano. Correlativamente, a modificação planejada de certas variáveis do ambiente social teria efeitos profiláticos e/ ou terapêuticos sobre os quadros psiquiátricos, o que tornaria sustentável teórica, prática e politicamente uma perspectiva de "Saúde Mental” em psiquiatria. Em um artigo de 1978, o professor Luiz Cerqueira descreveria Pernambucano como "um psiquiatra com alma de sanitarista, descompromissado com o modelo médicoprivado-curativo exclusivo" (Cerqueira, 1989, p. 25). Para melhor situarmos a contribuição desse psiquiatra brasileiro da primeira metade do século passado à problemática questão da prevenção no campo da psicopatologia, é preciso ter em mente o contexto histórico-político em que se inscreve sua obra. 
Ulysses Pernambucano de Mello Sobrinho nasceu em Recife, no dia 6 de fevereiro de 1892. Fez sua formação médica no Rio de Janeiro, onde se diplomou em 1912. Desde 1910, contudo, já freqüentava o serviço do professor Juliano Moreira, no Hospício Nacional de Alienados. Na “Seção Pinel”, ligada àquele hospital, teve a oportunidade de trabalhar sob a orientação de Ulisses Viana, que teria grande influência no começo de sua formação e sobre sua visão da psiquiatria. Em seu discurso proferido na Academia Nacional de Medicina, em abril de 1932, Ulysses Pernambucano afirma que, apesar de seus pendores psiquiátricos terem nascido sob o influxo de Juliano Moreira, "o homem que verdadeiramente [o] iniciou na psiquiatria foi o professor Ulisses Viana”.

Desses grandes mestres e do espírito reinante na psiquiatria daqueles tempos, Ulysses Pernambucano herdaria uma visão psiquiátrica fortemente ancorada na tradição kraepeliana, com sua ênfase na observação clínica, na investigação dos sinais distintivos das diferentes doenças mentais e, correlativamente, no estabelecimento do diagnóstico preciso. Mesmo em suas abordagens socioculturais e filosóficas mais elaboradas dos fenômenos mórbidos psíquicos, Ulysses Pernambucano manterá sempre uma concepção fundamentalmente médica da psiquiatria.

Logo após sua formatura, o jovem psiquiatra foi se instalar na cidade de Lapa, no interior do Paraná, retornando pouco tempo depois para Pernambuco, onde exerceu a medicina na pequena localidade de Vitória de Santo Antão. Esse período inicial de sua prática clínica colocou-o em contato direto com a realidade social da pobreza, da desnutrição, com as diferentes formas de desestruturação pessoal e familiar acarretadas pela miséria e pela falta de recursos públicos para a saúde e para a educação. Seu labor cotidiano nessas pequenas comunidades rurais do interior brasileiro era menos o de um psiquiatra com refinada formação, do que o de um médico generalista confrontado ao trabalho com crianças desnutridas, gestantes desassistidas, com a gritante desigualdade social brasileira e com a carência generalizada de recursos de saúde que o obrigava, por vezes, a exercer as atividades de dentista, de parteiro e mesmo de cirurgião. Tal exposição precoce e imediata à rude realidade de seus pacientes daria à sua concepção de “higiene mental” um caráter menos eugenista, como o que imperava em seu tempo, ${ }^{1}$ do que propriamente político-institucional, voltado à organização efetiva das ações médicas e governamentais no sentido de responder às condições sociais concretas - supostamente patogênicas ou implicadas nos processos mórbidos da população.

1. Sobre o papel das concepções eugenistas na Liga Brasileira de Higiene Mental e na psiquiatria brasileira do começo do século XX, remetemos ao livro de Jurandir Freire Costa, História da psiquiatria no Brasil. 
Como indica José Lucena, em importante artigo publicado em 1978, grande parte da produção escrita de Ulysses Pernambucano, “nesse período mais recuado, versou, compreensivelmente, sobre aspectos concernentes a fatores exógenos das psicoses e deficiência mental” (Lucena, 1978, p. 150). Aquela que viria a ser sua concepção de "prevenção primária” em saúde mental encontrava, assim, seus alicerces em fatores muito concretos relacionados ao surgimento de quadros mentais que poderiam chegar ao consultório do psiquiatra: a neurossífilis e outras infecções com repercussões neurológicas, o alcoolismo, as intoxicações exógenas, os malefícios decorrentes de desnutrição. Sua observação diária das dificuldades escolares oriundas da fome e da falta de alimentação adequada das crianças foi, certamente, um dos fatores que o levou a instituir, quando investido de funções públicas, um amplo programa de merenda escolar e de visitadoras familiares.

Ao regressar a Recife, em 1917, Ulysses Pernambucano passou a trabalhar no Hospício da Tamarineira, na época um vetusto hospital de doentes mentais, cujas condições extremamente precárias e de profunda carência de recursos financeiros impediam qualquer projeto terapêutico-assistencial. Além de atividades clínicas na Tamarineira, Ulysses Pernambucano assumiria o cargo de chefe do Serviço de Demografia Sanitária, Estatística e Propaganda de Depto. de Saúde Pública de Pernambuco, o que certamente contribuiu para ampliar sua visão sobre as relações entre a psicopatologia e os fenômenos sociais, bem como para desenvolver uma abordagem ao mesmo tempo científica e política das condições sociais concretas que interferiam nos quadros clínicos apresentados por seus pacientes. Ao longo de toda sua carreira, Ulysses Pernambucano teria especial interesse nos levantamentos estatísticos das condições de saúde geral e mental da população, chegando a propor a criação de um órgão nacional que centralizasse os dados disponíveis e que promovesse estudos regulares sobre epidemiologia psiquiátrica em todas as unidades da República. Segundo seu ponto de vista, somente com o apoio de tais informações - e com o uso de um mesmo critério para o diagnóstico das entidades mórbidas - seria possível estabelecer prioridades e uma política racional de prevenção e de organização de recursos assistenciais (a esse respeito, ver Pernanbucano, 1934).

No plano acadêmico-científico, inicialmente Ulysses Pernambucano foi nomeado professor Catedrático de Clínica Psiquiátrica em 1920, mas renunciou a esse posto em favor de Alcides Codeceira que já dirigia essa cadeira desde 1915 (cf. Piccinini, 2001). Em 1938 ocuparia, Faculdade de Medicina de Recife, a cátedra de Neurologia. Além disso, foi professor da Escola Normal, onde, a partir de 1918 ocupou, por concurso, a Cátedra de Psicologia e Pedologia e foi Catedrático de Psicologia, Lógica e História da Filosofia e do Ginásio Pernambucano. 
O período que se seguiu ao final da Primeira Guerra Mundial constituiu um marco na história da construção chamada "identidade nacional”. Diante da derrocada fratricida da Europa e dos valores por ela representados, colocava-se aos brasileiros o problema da definição do Brasil e de sua própria realidade. Lentamente a economia brasileira dirigia-se para a industrialização, com o conseqüente crescimento dos centros urbanos, nos quais se implantaria uma nascente preocupação com os direitos civis e do trabalhador. No plano das idéias assiste-se à Semana de Arte Moderna de 1922, ao Manifesto Antropofágico, ao florescimento da literatura com temáticas regionais. No início dos anos 1930, a publicação de “Casa Grande e Senzala”, de Gilberto Freyre, primo e interlocutor intelectual de Ulysses Pernambucano, constitui um patamar decisivo para a organização do olhar do Brasil sobre si mesmo. É embebida neste Zeitgeist, no qual a questão da realidade social brasileira é colocada em primeiro plano, que se inscreve a abordagem teórica e, sobretudo, prática de Ulysses Pernambucano das relações entre psicopatologia e sociedade, com suas conseqüências para a elaboração de propostas preventivo-assistenciais coerentes e efetivas.

Extremamente interessado pelas questões culturais relacionadas à psicopatologia, em particular por meio dos trabalhos de Antropologia Psiquiátrica de Raimundo Nina-Rodrigues, Ulysses Pernambucano dedicou-se ao estudo das condições de doença mental dos negros no Brasil. Em 1934 foi um dos principais incentivadores e articuladores do $1^{\circ}$ Congresso Afro-Brasileiro, organizado em Recife por Gilberto Freyre, evento que teve profundas conseqüências para os debates sobre as raízes africanas da cultura brasileira, reconhecendo e legitimando a participação do negro e dos mestiços no processo de construção do Brasil enquanto nação. Nesse Congresso, Ulysses Pernambucano apresentou um trabalho intitulado “As doenças mentais entre os negros de Pernambuco”, no qual mostrava, de um ponto de vista estatístico, que os negros pernambucanos eram menos susceptíveis que os brancos às psicoses constitucionais, embora apresentassem índices superiores de freqüência de psicoses tóxicas. ${ }^{2}$ Nesse trabalho, Ulysses Pernambucano não propõe qualquer hipótese interpretativa de seus resultados, limitando-se à constatação dos dados obtidos.

2. Do ponto de vista nosográfico, Ulysses Pernambucano dividia os transtornos mentais em três grandes grupos: 1) as psicopatias constitucionais (que incluíam a psicose maníaco-depressiva, as psicoses degenerativas, a esquizofrenia e os quadros paranóicos); 2) as psicopatias com lesão orgânica definida (como a epilepsia, a psicose de involução, as psicoses por lesões cerebrais - tais como a neurossífilis e as demências arteroescleróticas - e as oligofrenias; 3) e as psicopatias decorrentes de auto e hetero-intoxicação (alcoolismo, morfinomania) e as psicoses causadas por toxinas microbianas. 
Foi, igualmente, um defensor do direito ao exercício de religiões afrobrasileiras, em um momento histórico em que estas eram objeto de intensas perseguições pelas forças de ordem pública. Dessa forma, sua visão ampla das relações entre cultura e psicopatologia em muito contribuiu para o descentramento dos debates antropológico-psiquiátricos, na época cristalizados nas teorias sobre a suposta superioridade da raça branca, sobre a degenerescência engendrada pela mestiçagem e sobre a correspondente necessidade de “arianização” da população brasileira para a melhora global das condições de saúde e de cidadania no país, em direção a uma concepção mais sensível aos elementos sociais propriamente ditos, efetivos no surgimento e na manutenção dos transtornos mentais mais freqüentes no âmbito da ação psiquiátrica.

Em 1924, Ulysses Pernambucano assume a direção da Tamarineira, dando origem a reformas de infra-estrutura e de funcionamento de grande repercussão. Não apenas as condições físicas das instalações são melhoradas e modernizadas, como também começa a ser implantada uma política ativa de desinstitucionalização e de reintegração do paciente à família de origem. Sua permanência nessas funções foi relativamente curta - dois anos -, mas deixou marcas duradouras: foram desativados os calabouços onde eram trancafiados os pacientes considerados "perigosos", instituiu-se um pavilhão de “observação de pacientes" e um moderno serviço de hidroterapia. A humanização do atendimento ao paciente psiquiátrico passa a ser encarada como necessidade elementar para a organização dos serviços de assistência. Ao mesmo tempo, o hospital começa a realizar pesquisa científica de forma sistemática.

Com a vitória da Revolução de 1930, Ulysses Pernambucano foi novamente nomeado para a direção daquele Hospital, dessa vez contando com mais poderes para concluir sua tarefa de reforma, modernização e humanização.

Em 1931, ele cria a Divisão de Assistência a Psicopatas de Pernambuco implantando um plano de atendimento psiquiátrico e de pesquisa altamente inovador para sua época, que incluía a atenção especializada a pacientes agudos, um ambulatório e serviço aberto, a criação de colônias agrícolas para os crônicos - com incentivo à autogestão por parte dos pacientes -, a criação de um manicômio judiciário, bem como a instalação de serviços de estatística e de profilaxia. Este daria origem aos serviços de Higiene Mental de Pernambuco, um dos pioneiros nessa área no Brasil.

O trabalho de Ulysses Pernambucano visava, assim, realizar, no plano prático, intervenções de caráter preventivo e terapêutico que levassem em conta concretamente as relações do paciente com seu meio socioeconômico e cultural. Resultava daí uma concepção ampla da "ação social do psiquiatra”, expressão que serve de título à conferência pronunciada por ele, na abertura do $3^{\circ}$ Congresso da Sociedade de Neurologia, Psiquiatria e Higiene Mental do Nordeste, ocorrido 
em Natal, entre 12 e 16 de outubro de 1943, algumas semanas antes de sua morte. Essa conferência é aqui reproduzida integralmente e permite ter uma visão geral sobre sua posição face a essa questão.

Tal maneira de conceber o fenômeno psicopatológico e as formas de intervenção de caráter médico-social que dela decorriam, deram origem ao que ficou conhecido como “Escola da Psiquiatria Social do Recife”, de grande importância nos destinos da psiquiatria social brasileira e que teve em Ulysses Pernambucano a figura de referência maior. Essa perspectiva de concepção do campo psiquiátrico tinha, segundo Heronides Coelho Filho (1953), as seguintes características principais:

a) a idéia de que “a psiquiatria não é uma simples ciência mental. (...) É uma verdadeira integração das diferentes ciências do espírito”, apresentado assim, "uma tendência integradora, unificadora e sintética".

b) A ênfase da perspectiva social relacionada aos fatos psiquiátricos, incluindose aí os estudos psicopatológicos referidos diretamente a fenômenos socioculturais, a busca de levantamentos estatísticos desses fenômenos e a ênfase na "neuro-higiene".

c) “o aspecto tipicamente local, regional, de seus estudos”.

Em decorrência do Movimento Comunista de 1935, Ulysses Pernambucano foi mantido quarenta dias em prisão, tendo sido acusado de comunismo, de divulgar idéias subversivas entre seus alunos e "pelo simples fato de ler Freud" (cf. Freitas Jr., 1953, p. 439). Um dos motivos para sua queda em desgraça junto às autoridades locais, segundo relata Valdemar Valente (1953, p. 444) a partir de informações obtidas de Gilberto Freyre, teria sido o fato de Pernambucano pretender "a realização de um inquérito de caráter sociológico sobre as condições de vida e de trabalho nas usinas do Nordeste”, projeto que teria provocado a fúria e uma "forte reação de alguns líderes da indústria de açúcar de Pernambuco" (Gilberto Freyre, citado por Valente, 1953, p. 439), o que terminou por impedir sua efetivação. ${ }^{3}$ Posto em liberdade pelo Tribunal de Segurança Nacional, Ulysses Pernambucano foi ainda assim proibido de reassumir funções administrativas no Hospital da Tamarineira.

Em junho de 1938, cria a revista Neurobiologia, um dos mais antigos e respeitados veículos científicos do campo psiquiátrico, ainda em circulação no Brasil.

3. Afirma Fernando de Mello Freyre (1989): "Durante alguns anos, Gilberto [Freyre] pensou em fundar no Recife com Ulysses Pernambucano, um Instituto de Pesquisas que desse do Nordeste e particularmente de Pernambuco uma visão de sua realidade social”. 
Ulysses Pernambucano falece no Rio de Janeiro no dia 5 de dezembro de 1943 em virtude de complicações cardíacas relacionadas a um infarto que sofrera sete anos antes e que o colocara, desde então, em um quadro de saúde muito frágil. Deixa o legado de um trabalho pioneiro, que marcaria profundamente a reforma da assistência psiquiátrica no Brasil e que contribuiria para uma concepção mais ampla e conseqüente das relações entre a realidade social nacional e as formas específicas do sofrimento psíquico e de seu cuidado.

\section{Referências}

Altino, E. Noticiário - Décimo aniversário da morte do professor Ulysses Pernambucano / Discurso do professor Edgar Altino. Neurobiologia, t. XVI, n. 4, p. 449-52, 1953. Cerqueira, L. Raízes e tendências da psiquiatria social no Brasil. In: Psiquiatria social - problemas brasileiros de saúde mental. Rio de Janeiro: Livraria Atheneu, 1989. p. 23-4.

Coelno Filho, H. Origem e desenvolvimento da assistência a psicopatas no Estado de Pernambuco - Ulysses Pernambucano. Neurobiologia, t. XVI, n. 4, p. 419-35, 1953.

Costa, J. F. História da psiquiatria no Brasil. 4. ed. Rio de Janeiro: Xenon, 1989.

Freitas Jr., O. Noticiário - Décimo aniversário da morte do professor Ulysses Pernambucano / Discurso do Dr. Otávio Freitas Jr. Neurobiologia, t. XVI, n. 4, p. 439-41, 1953. Freyre, F. M. Tropicologia, civilização brasileira e fundação Joaquim Nabuco. Biblioteca Virtual de Tropicologia. Disponível em:

http://www.tropicologia.org.br/conferencia/1989tropicologia_civilizacao.html

Lucena, J. Ulysses Pernambucano e sua escola de psiquiatria social. Academia Pernambucana de Medicina, Ciclo de estudos sobre Ulysses Pernambucano, Recife, 1978, p. 145-75.

Pernambucano, U. (1934). As doenças mentaes entre os negros de Pernambuco. In: Estudos afro-brasileiros - Trabalhos apresentados no $1^{\circ}$ Congresso afro-brasileiro de Recife. Recife: Fundação Joaquim Nabuco/Editora Massangana, 1988. p. 93-8.

As doenças mentaes entre os negros de Pernambuco; Recursos modernos de assistência aos doentes mentais. Neurobiologia, t. I, n. 1, p. 1-13, 1938.

A ação social do psiquiatra. Neurobiologia, t. VI, n. 4, p. 153-60, 1943.

Piccinini, W. Voando sobre a psiquiatria brasileira: Ulysses Pernambucano (1892-1943). Psychiatry On-line Brazil (6) fevereiro 2001, http://www.polbr.med.br/arquivo/ wal0201.htm 